Научная статья

УДК 631.43:930.3

DOI 10.18101/2587-7143-2021-3-14-20

\title{
ФИЗИЧЕСКИЕ СВОЙСТВА АЛЛЮВИАЛЬНОЙ ЛУГОВОЙ ПОЧВЫ СУХОСТЕПНОЙ ЗОНЫ ЗАПАДНОГО ЗАБАЙКАЛЬЯ
}

\section{(С) Ильин Юрий Михайлович}

кандидат сельскохозяйственных наук, доцент кафедры мелиорации и охраны земель, Бурятская государственная сельскохозяйственная академия им. В. Р. Филиппова Россия, 670024, г. Улан-Удэ, ул. Пушкина, 8

ilbar50@mail.ru

(C) Мангатаев Александр Цыренович

кандидат биологических наук, ведущий инженер

лаборатории географии и экологии почв,

Институт общей и экспериментальной биологии СО РАН

Россия, 670047, г. Улан-Удэ, ул. Сахьяновой, 6

aleksandr_man@mail.ru

\begin{abstract}
Аннотация. Свойства почвы как единого физического тела во многом определяются составом, соотношением, взаимодействием и динамикой твердой, жидкой, газообразной и живой фаз. В этом аспекте особую роль играют физические свойства почвы. К ним относятся общие физические, физико-механические, водные, воздушные, тепловые свойства, структура. Физические свойства влияют на характер почвообразовательного процесса, плодородие почвы и развитие растений. Под влиянием орошения поливными водами существенно изменяются агрономические свойства почвы, водновоздушный, тепловой и питательный режимы, микробиологическая активность почвы, микроклимат над орошаемой территорией. Необходимость в мелиорациях определяется для каждой территории зональными особенностями и конкретными хозяйственными задачами. Поддержание влажности почвы в оптимальном интервале (в спелом состоянии) способствует образованию структуры. Целью работы было изучение влияния сельскохозяйственного освоения залежи и оросительной мелиорации на свойства аллювиальной луговой почвы Западного Забайкалья. Объектом исследования являлась аллювиальная луговая почва Иволгинской котловины. Предметом исследований послужило изменение морфологической структуры и основных физических свойств почвы при воздействии орошения и обработки почвы. В качестве контроля была выбрана залежь. Свойства почвы определялись по общепринятым в почвоведении методикам.
\end{abstract}

Ключевые слова: гранулометрический состав почв, залежь, морфологические свойства, орошение, пашня, физические свойства.

\section{Для цитирования}

Ильин Ю. М., Мангатаев А. Ц. Физические свойства аллювиальной луговой почвы сухостепной зоны Западного Забайкалья // Вестник Бурятского государственного университета. Биология, география. 2021. № 3. С. 14-20.

Введение. Потенциальное и эффективное плодородие почвы как полипараметрическое системное свойство в значительной степени определяется физическими свойствами [1]. Их изучение позволяет выявить генетические и агромелиоративные особенности и определить те из них, которые нуждаются в направ- 
Ю. М. Ильин, А. Ц. Мангатаев. Физические свойства аллювиальной луговой почвы сухостепной зоны Западного Забайкалья

ленном изменении для нужд сельскохозяйственных растений. В связи с этим большое значение приобретает установление оптимальных параметров наиболее жизненно важных для растений физических особенностей почв. Кроме того, в засушливых экологических условиях степной зоны Западного Забайкалья первоочередным параметром оптимизации являются водные константы и режимы почв, которые определяются их физическими свойствами.

Цели и задачи. Целью работы было изучение влияния вспашки и орошения на агрофизические свойства аллювиальной луговой почвы Иволгинской котловины Западного Забайкалья.

В ходе исследований решались следующие задачи:

- определить изменение в морфологической структуре почвы при обработке почвы и орошения;

- изучить гранулометрический состав почвы;

- определить влияние оросительной мелиорации и вспашки на плотность сложения почвы.

Объекты и методы. Объектом исследований является аллювиальная луговая почва Иволгинской котловины Западного Забайкалья. Предметом исследования служило изменение морфологической структуры и основных физических свойств почвы под влиянием сельскохозяйственного освоения и оросительной мелиорации.

Исследование свойств почвы проводилось на залежи, орошаемой пашне, и частично на целине. В качестве контроля выступает залежь. Исследования проводились общепринятыми в почвоведении методиками [2].

Экспериментальная часть и обсуждение результатов. Сельскохозяйственное освоение и оросительная мелиорация являются основными дезинтеграторами нарушения внутренних связей почвенных систем. Этими дезинтеграторами являются редукционные антропогенные технологии, которые влияют на морфологическую структуру почвы и определяют степень хаотизации ее внутренней структуры.

Из особенностей морфологического строения аллювиальной луговой почвы Иволгинской котловины необходимо отметить, что гумусовый аккумулятивный горизонт залежи за 28 лет покоя достигает мощности до 55 см в сравнении с целинными аналогами, где гумусовый горизонт составляет 60 см. Он менее мощный. Применение же орошения в сочетании с пахотой в течение этих же лет сокращает гумусовый слой до 41 см. Следует считать, что залежная форма накопления органического вещества (OB) подчиняется правилу роста дневной поверхности почвы. Это означает, что на залежи наблюдается инситная форма накопления $\mathrm{OB}$, в то время как на орошаемой пашне происходит уменьшение гумусового слоя за счет разрушения гумуса и гуминовые кислоты (ГК) нисходящими токами оросительных вод прокрашивают нижние подпахотные слои почвы затеками, что затрудняет определение переходной границы в почвенном разрезе. Длительное орошение предопределяет возрастание подвижных форм ГК в верхней части профиля почвы и их миграцию до глубины 90-100 см [2; 3]. Известно, что эрозионные процессы становятся острой проблемой при распахивании земель. Вспаханная и хорошо разрыхленная почва легко смывается и максимально подвержена дефляции $[8 ; 10]$. Экологически опасная хозяйственная деятельность человека 
активизирует природные эрозионные процессы. Результатом этой деятельности являются снижение мощности гумусового горизонта, переуплотнение подпахотных горизонтов, укрупнение структурных агрегатов и дегумификация [4-6]. Так, в процессе использования залежи под пахотные земли и применения орошения содержание гумуса в аккумулятивном горизонте исследуемой почвы снижается с 5,68 до 4,26\%.

Таким образом, наблюдается псевдоморфометрическое увеличение гумусного горизонта пашни аллювиально-луговой почвы.

Гранулометрический состав — важнейшая генетическая и агромелиоративная характеристика почв, по которой в значительной степени определяются их физические и водные свойства. При определении гранулометрического состава под различными способами использования аллювиальной луговой почвы выявлены некоторые различия (табл. 1).

Результаты исследования гранулометрического состава показывают, что в верхних слоях (0,3 м) залежной аллювиальной луговой почвы скелетные частицы составляют в среднем $18,63 \%$ общей массы с максимальным количеством в горизонте 10-20 см - 25,42\%. В этой же почве, находящейся под пашней, содержание скелетных частиц составляет еще больше - 26,0\%. Обращает внимание то, что скелетная часть верхнего слоя (0-10 см) пашни увеличивается в 2,4 раза в сравнении с аналогичным горизонтом залежи.

Повышение скелетности пахотных почв объясняется выносом тонкодисперсных частиц из пахотного слоя почвы инфильтрующейся оросительной влагой, а также выдуванием их в процессе дефляции.

Таблица 1

Гранулометрический состав аллювиальной луговой почвы под залежью и пашней, 2010 г.

\begin{tabular}{|c|c|c|c|c|c|c|c|c|c|}
\hline \multirow{2}{*}{$\begin{array}{l}\text { Глубина } \\
\text { отбора, см }\end{array}$} & \multicolumn{8}{|c|}{ Содержание фракций, \% от абсолютно сухой почвы, мм } & \multirow[b]{2}{*}{ Индекс } \\
\hline & $1,0-0,25$ & $0,25-0,05$ & $0,05-0,01$ & $0,01-0,005$ & $0,005-0,001$ & $<0,001$ & $<0,01$ & $>0,01$ & \\
\hline \multicolumn{10}{|c|}{ Залежь } \\
\hline $0-10$ & 1,14 & 12,75 & 52,43 & 10,61 & 16,40 & 6,67 & 33,68 & 66,32 & Ccp \\
\hline $10-20$ & 1,58 & 25,42 & 40,68 & 11,12 & 13,77 & 7,43 & 32,32 & 67,68 & Cср \\
\hline $20-30$ & 0,81 & 14,20 & 39,44 & 13,18 & 17,35 & 15,26 & 45,79 & 54,21 & CT \\
\hline $30-40$ & 0,16 & 7,53 & 41,94 & 14,14 & 20,99 & 15,24 & 50,37 & 49,63 & CT \\
\hline $40-50$ & - & 2,73 & 53,70 & 12,44 & 19,92 & 11,21 & 43,57 & 56,43 & Ccp \\
\hline $50-60$ & - & 22,55 & 41,58 & 12,59 & 16,64 & 6,94 & 35,87 & 64,13 & Ccp \\
\hline $60-70$ & - & 25,88 & 44,35 & 9,45 & 12,59 & 7,73 & 29,77 & 70,23 & Сл \\
\hline $70-80$ & 0,09 & 16,88 & 49,12 & 12,28 & 15,59 & 6,04 & 33,91 & 66,09 & Ccp \\
\hline $80-90$ & 0,15 & 20,19 & 50,33 & 10,20 & 11,91 & 7,22 & 29,33 & 70,67 & Сл \\
\hline $90-100$ & 0,52 & 58,49 & 25,25 & 4,61 & 5,90 & 5,29 & 15,80 & 84,20 & Сл \\
\hline \multicolumn{10}{|c|}{ Пашня орошаемая } \\
\hline $0-10$ & 1,14 & 32,29 & 40,84 & 9,24 & 11,12 & 5,37 & 25,73 & 74,27 & Сл \\
\hline $10-20$ & 1,32 & 25,22 & 41,82 & 10,26 & 15,10 & 6,28 & 31,64 & 68,36 & Cсp \\
\hline
\end{tabular}


Ю. М. Ильин, А. Ц. Мангатаев. Физические свойства аллювиальной луговой почвы сухостепной зоны Западного Забайкалья

\begin{tabular}{|l|l|l|l|l|l|l|l|l|l|}
\hline $20-30$ & 0,31 & 17,48 & 42,23 & 13,48 & 18,40 & 8,10 & 39,98 & 60,02 & Сср \\
\hline $30-40$ & 0,14 & 10,64 & 41,55 & 15,46 & 23,66 & 8,55 & 47,67 & 52,33 & Ст \\
\hline $40-50$ & 0,05 & 10,70 & 46,02 & 18,18 & 19,07 & 5,98 & 43,23 & 56,77 & Сср \\
\hline $50-60$ & - & 14,48 & 44,29 & 16,28 & 19,38 & 5,57 & 41,23 & 58,77 & Сср \\
\hline $60-70$ & - & 25,83 & 43,45 & 11,18 & 13,18 & 6,36 & 30,72 & 69,28 & Сср \\
\hline $70-80$ & - & 12,20 & 50,08 & 14,22 & 17,40 & 6,10 & 37,72 & 62,28 & Сср \\
\hline $80-90$ & 0,13 & 7,46 & 50,73 & 17,07 & 19,03 & 5,71 & 41,81 & 58,19 & Сср \\
\hline $90-100$ & 0,26 & 28,98 & 46,52 & 6,69 & 12,06 & 5,49 & 24,24 & 75,76 & Сл \\
\hline
\end{tabular}

Вместе с тем обращают внимание высокое содержание крупной пыли $(0,05-$ $0,01)$, ее заметная дифференцированность в профиле почвы залежи и монотонность осадконакопления с поверхности пахотной почвы до глубины 60-70 см, что связано с перераспределением фракций крупной пыли под воздействием оросительной воды. Оптимальный водный режим почвы поддерживается для слоя 0-60 см не ниже 70\% НВ, в результате инфильтрующими оросительными водами в нижние слои (70-80, 80-90 и 90-100 см) пахотной почвы вымывается «физическая глина» и их количество в этих слоях увеличивается на $11,2,42,5$ и 52,2\% в сравнении с контрольным вариантом. Обогащение отмеченных нижних слоев пахотной почвы «физической глиной» утяжеляет их и меняет индексы гранулометрического состава. В то же время верхний (0-10 см) слой пахотной почвы превращается из среднего суглинка в суглинок легкий, а на глубине 20-30 см суглинок тяжелый трансформируется в суглинок средний.

Плотность сложения гумусового горизонта аллювиальной луговой почвы невысокая (табл. 2), что связано с повышенным содержанием в нем органического вещества. Особенно невелика плотность залежной почвы в верхнем полуметровом слое залежи.

Таблица 2

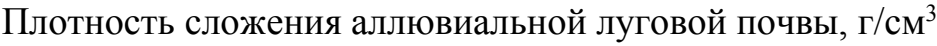

\begin{tabular}{|c|c|c|c|}
\hline \multirow{2}{*}{ Глубина отбора, см } & \multicolumn{2}{|c|}{ Залежь } & Пашня \\
\cline { 2 - 4 } & 2006 & 2010 & 2010 \\
\hline $0-10$ & 0,97 & 0,87 & 0,91 \\
\hline $10-20$ & 0,89 & 0,88 & 0,96 \\
\hline $20-30$ & 0,91 & 0,99 & 1,07 \\
\hline $30-40$ & 0,88 & 0,89 & 1,21 \\
\hline $40-50$ & 0,87 & 0,89 & 1,18 \\
\hline $50-60$ & 1,12 & 1,16 & 1,26 \\
\hline $60-70$ & 1,19 & 1,18 & 1,34 \\
\hline $70-80$ & 1,36 & 1,37 & 1,37 \\
\hline $80-90$ & 1,31 & 1,33 & 1,24 \\
\hline $90-100$ & 1,28 & 1,32 & 1,36 \\
\hline
\end{tabular}


Среднее ее значение на контрольном варианте в 2006 г. в слоях 0-20 см и

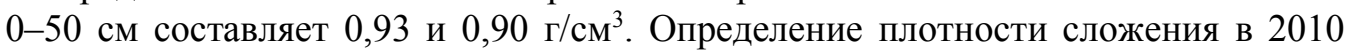
году на залежи в этих слоях показывает незначительные изменения в слое 0-10 см, что связано с привносом органического вещества отмирающими растительными остатками. В слое 10-50 см залежи изменения плотности сложения незначительны. Для контрольного варианта характерно заметное увеличение плотности вглубь по профилю ниже отметки 50 см.

Использование залежи под пашню с одновременным применением орошения увеличивает плотность почвы по всему профилю в сравнении с контрольным вариантом. В обрабатываемой почве пахотный слой (0-20 см) имеет недостаточную плотность, особенно в верхней части $\left(0,91\right.$ г/ $\left.\mathrm{cm}^{3}\right)$. Считая, что оптимальная для зерновых культур плотность слоя среднесуглинистых почв равна

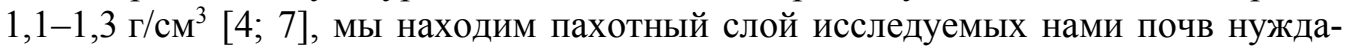
ющимся в дополнительном уплотнении.

Вместе с тем для пахотного слоя пашни (20-30 см) характерно повышение величины плотности, что, очевидно, связано с образованием здесь плужной подошвы, а также с инфильтрационным выносом мелкозема из пахотного слоя оросительными водами (табл. 1). Вследствие этого верхний (0-70 см) слой пашни в отличие от залежи более уплотнен. В этом отношении показательны исследования [5], в которых выявлена повышенная плотность до глубины 0,5 м луговочерноземной почвы Западного Забайкалья. Это означает, что значительный вклад в увеличение плотности аллювиальной луговой почвы вносит применение оросительной мелиорации.

Таким образом, плужная обработка и орошение благоприятно воздействуют на подпахотный слой (20-30 см) и глублежащие слои (30-60 см) почвы, где плотность $(1,07-1,26$ г/см³) становится благоприятной для роста и развития зерновых культур [4].

\section{Выводы}

1. Гумусовый горизонт аллювиальной луговой почвы под залежью достигает 55 см, в то время как на целине ее мощность равна $60 \mathrm{~cm}$.

2. В залежной аллювиальной луговой почве гранулометрический состав в основном сложен из средних суглинков, на глубине 20-30 и 30-40 см превалирует тяжелый суглинок, в слое 90-100 см - супеси.

3. Под влиянием обработки почвы и орошения происходит сепарация гранулометрического состава, так тяжелый суглинок на глубине 20-30 см трансформируется в средний, одновременно утяжеляя нижний слой (30-40 см) и превращая суглинок легкий на глубине 60-70 см в суглинок средний.

4. Перераспределение частиц вниз по профилю почвы в процессе антропогенного производства приводит к изменению ее плотности сложения с глубины 30 см до отметки $70 \mathrm{~cm}$.

5. Обработка почвы и оросительная мелиорация на первых этапах освоения залежи в течение 4 лет положительно воздействуют на изменение гранулометрического состава и плотности сложения аллювиальной луговой почвы за счет переноса и вмывания тонкодисперсных частиц почвы в ее нижние горизонты.

6. Одновременно наблюдается четкая тенденция опесчанивания пахотного слоя исследуемой почвы, которая требует решения. 
Ю. М. Ильин, А. Ц. Мангатаев. Физические свойства аллювиальной луговой почвы сухостепной зоны Западного Забайкалья

\section{Литература}

1. Апарин Б. Ф. Плодородие как функциональная система // Почва и их биологическая продуктивность. Тарту: Изд-во Эстонской с.-х. акад., 1979. С. 19-20. Текст: непосредственный.

2. Базаров Д.-Д. Б. Кайнозой Прибайкалья и Западного Забайкалья. Новосибирск: Наука, 1986. 172 с. Текст: непосредственный.

3. Беховых Ю. В. Физические свойства чернозема южного под некоторыми древесными породами полезащитных лесополос // Вестник Алтайского государственного университета. 2017. № 10. С. 49-53. Текст: непосредственный.

4. Вадюнина А. Ф., Корчагина 3. А. Методы исследования физических свойств почв. Москва: Агропромиздат, 1986. 416 с. Текст: непосредственный.

5. Ковалева Е. И. Изменение гумуса сухостепных почв во времени при орошении (на примере Кулундинской степи): автореферат диссертации на соискание ученой степени кандидата биологических наук. Новосибирск, 1997. 19 с. Текст: непосредственный.

6. Куликов А. И., Панфилов В. П., Дугаров В. И. Физические свойства и режимы лугово-черноземных почв Бурятии. Новосибирск: Наука, 1986. 136 с. Текст: непосредственный.

7. Антропогенная трансформация пахотных почв степной зоны Алтайского края / Г. Г. Морковкин, Т. В. Байкалов, Н. Б. Максимова и др. // Вестник Алтайского государственного аграрного университета. 2014. № 6. С. 43-48. Текст: непосредственный.

8. Ногина Н. А. Почвы Забайкалья. Москва: Наука, 1964. 314 с. Текст: непосредственный.

9. Ревут И. Б. Физика почв. Ленинград: Колос, 1972. 366 с. Текст: непосредственный.

10. Разнообразие почв Иволгинской котловины: эколого-агрохимические аспекты / Л. Л. Убугунов, И. Н. Лаврентьева, В. И. Убугунова, М. Г. Меркушева. Улан-Удэ: Изд-во БГСХА им. В. Р. Филиппова, 2000. 208 с. Текст: непосредственный.

Статья поступила в редакцию 02.09.2021; одобрена после рецензирования 06.09.2021; принята к публикации 01.10.2021.

\section{PHYSICAL PROPERTIES OF ALLUVIAL MEADOW SOIL IN THE DRY STEPPE ZONE OF WESTERN TRANSBAIKALIA}

Yury M. Ilyin

Cand. Sci. (Agriculture), A/Prof. of Land Reclamation and Protection Department, Filippov Buryat State Agricultural Academy

8 Pushkina St., Ulan-Ude 670024, Russia

ilbar50@mail.ru

Aleksandr Ts. Mangataev

Cand. Sci. (Biol.), Leading Engineer,

Laboratory of Geography and Ecology of Soils,

Institute of General and Experimental Biology SB RAS

6 Sakhyanovoy St., Ulan-Ude 670047, Russia

aleksandr_man@mail.ru

Abstract. The properties of soil as a single physical body are largely determined by the composition, correlation, interaction and dynamics of solid, liquid, gaseous and alive phases. In this regard, the physical properties of soil play a special role. They include general physical, physicomechanical, water, air, thermal properties, and structure. Physical properties affect the nature of the soil-forming process, soil fertility and plant development. The 
agronomic properties of the soil, water-air, heat and nutritional regimes, microbiological activity, and the microclimate over the irrigated area change significantly under the influence of irrigation. The need for land reclamation is determined for each territory by zonal features and specific economic tasks. Maintaining soil moisture in the optimal interval (in the ripe state) contributes to the formation of the structure. The article is aimed at studying the influence of agricultural development of the deposit and irrigation reclamation on the properties of the alluvial meadow soil of Western Transbaikalia. The object of the study is the alluvial meadow soil of Ivolginskaya Depression. The subject of research is changes in the morphological structure and basic physical properties of the soil under the influence of irrigation and cultivation. We have selected deposit as a sample for reference. The properties of the soil have been determined according to the standard methods of soil science.

Keywords: granulometric composition of soils, deposit, morphological properties, irrigation, arable land, physical properties.

For citation

Ilyin Yu. M., Mangataev A. Ts. Physical Properties of Alluvial Meadow Soil in the Dry Steppe Zone of Western Transbaikalia. Bulletin of Buryat State University. Biology, Geography. 2021; 3: 14-20 (In Russ.).

The article was submitted 02.09.2021; approved after reviewing 06.09.2021; accepted for publication 01.10.2021. 